\title{
KAJIAN KUAT TARIK LANGSUNG DAN KUAT TARIK BELAH BETON DENGAN FLY ASH KADAR 15\%, 30\%, DAN 40\% SEBAGAI PENGGANTI SEMEN TERHADAP BETON NORMAL
}

\author{
Agus Setiya Budi ${ }^{1)}$, Purwanto ${ }^{2)}$, Aninggito Wiku Cahyo Aji ${ }^{3)}$ \\ 1),2) Dosen Program Studi Teknik Sipil, Fakultas Teknik, Universitas Sebelas Maret \\ 3) Mahasiswa Program Studi Teknik Sipil, Fakultas Teknik, Universitas Sebelas Maret \\ Program Studi Teknik Sipil, Fakultas Teknik, Universitas Sebelas Maret Surakarta \\ Jl. Ir. Sutami 36A, Kentingan Surakarta 57126, Telp 0271-634524 \\ Email: ajiwiku11@gmail.com
}

\begin{abstract}
In the current era, where the environmental care movement is booming, large-scale mining has begun to be reduced, so it is necessary to think about procuring new types of aggregate sources that can be renewed in the manufacture of concrete. Concrete is an important component in the construction of infrastructure. The concrete manufacturing industry that still uses portland cement as the main raw material choice can trigger damage to the environment. Damage to the environment can occur due to carbon dioxide emissions from burning coal in the manufacture of portland cement. One alternative solution to replace portland cement is to use coal combustion residue, namely fly ash to improve the quality of concrete and reduce the negative impact on the environment. In this study, an analysis of the direct tensile strength and split tensile strength of concrete using fly ash content of $15 \%, 30 \%$, and $40 \%$ were carried out as a substitute for cement with the dimensions of the direct tensile strength test object $10 \times 10 \times 25 \mathrm{~cm}$ in the form of a beam with a center The span has a triangular shape with dimensions of $1.5 \mathrm{~cm}$ high and a base of $2 \mathrm{~cm}$ functioning as an area that is expected to fail and the test object for split tensile strength is a cylinder of $15 \mathrm{~cm}$ and a height of $30 \mathrm{~cm}$. The direct tensile strength test uses the load controlled test method using the UTM (Universal Testing Machine), while the split tensile strength test uses the CTM (Compression Testing Machine) tool, the test is carried out after the concrete hardens at the age of 28 days. The direct tensile strength value is smaller than the split tensile strength value in the variation of $15 \%$ fly ash content and normal concrete with a comparison of the direct tensile strength value in the $15 \%$ fly ash variation of $79.47 \%$ of the split tensile strength and the normal concrete variation. of $82 \%$ of the split tensile strength, while the direct tensile strength value is greater than the split tensile strength value, the 30\% fly ash variation is $123.37 \%$ of the split tensile strength and the $40 \%$ fly ash variation is $123.29 \%$ of split tensile strength.
\end{abstract}

Keywords: Fly ash, direct tensile strength, split tensile strength, fly ash concrete.

\begin{abstract}
Abstrak
Dalam era saat ini, dimana sedang maraknya dilakukan gerakan peduli lingkungan, penambangan besar-besaran mulai diusahakan untuk dikurangi, sehingga perlu dipikirkan pengadaan jenis sumber agregat baru yang dapat diperbaharui dalam pembuatan beton. Beton menjadi salah satu komponen penting dalam pembangunan suatu infrastruktur. Industri pembuatan beton yang masih menggunakan semen portland sebagai pilihan bahan baku utamanya dapat memicu kerusakan terhadap lingkungan. Kerusakan terhadap lingkungan dapat terjadi disebabkan emisi karbon dioksida yang berasal dari pembakaran batu bara dalam pembuatan semen portland. Salah satu alternatif solusi untuk menggantikan semen portland yaitu menggunakan residu pembakaran batu bara yaitu fly ash guna meningkatkan kualitas beton dan mengurangi dampak buruk terhadap lingkungan. Pada Penelitian ini dilakukan analisis kuat tarik langsung dan kuat tarik belah pada beton menggunakan kadar fly ash $15 \%, 30 \%$, dan 40\% sebagai bahan pengganti dari semen dengan dimensi benda uji pengujian kuat tarik langsung $10 \times 10 \times 25$ $\mathrm{cm}$ berbentuk balok dengan ditengah bentang terdapat cuilan dengan bentuk segitiga dengan dimensi tinggi $1,5 \mathrm{~cm}$ dan alas 2 $\mathrm{cm}$ berfungsi sebagai area yang diharapkan gagal dan benda uji pengujian kuat tarik belah berupa silinder $15 \mathrm{~cm}$ dan tinggi 30 $\mathrm{cm}$. Pengujian kuat tarik langsung menggunakan metode load controlled test dengan menggunakan alat UTM (Universal Testing Machine), sedangkan pengujian kuat tarik belah menggunakan alat CTM (Compression Testing Machine), pengujian dilaksanakan pasca beton mengeras pada umur 28 hari. Nilai kuat tarik langsung lebih kecil dibandingkan dengan nilai kuat tarik belah pada variasi kadar fly ash kadar 15\% dan beton normal dengan perbandingan nilai kuat tarik langsung pada variasi fly ash kadar $15 \%$ sebesar 79,47\% dari kuat tarik belah dan pada variasi beton normal sebesar $82 \%$ dari kuat tarik belahnya, sedangkan nilai kuat tarik langsung lebih besar dibandingkan dengan nilai kuat tarik belah, pada variasi fly ash kadar 30\% sebesar 123,37 \% dari kuat tarik belah dan pada variasi fly ash kadar 40\% sebesar 123,29\% dari kuat tarik belah.
\end{abstract}

Kata kunci : Fly ash, kuat tarik langsung, kuat tarik belah, beton fly ash.

\section{PENDAHULUAN}

Dalam Rencana Pembangunan Jangka Menengah Nasional IV 2020-2024, sektor konstruksi dan bangunan di Indonesia saat ini mengalami lonjakan nilai yang terus naik dan menunjukan kinerja yang luar biasa dilihat dari 
berkembangnya pembangunan yang telah berjalan dan selalu meningkat setiap tahunnya. Data infrastruktur ekonomi menyebutkan bahwa terdapat 16.579 Bank Umum Pemerintah, 8.022 Bank Umum Swasta, dan 7.848 Bank Perkreditan Rakyat. Sedangkan jumlah pasar di Indonesia adalah sebanyak 12.254 pasar dengan bangunan semi permanen, 9.688 pasar dengan bangunan permanen, dan 7.673 pasar tanpa bangunan. Fasilitas akomodasi di Indonesia, tersedia 12.558 hotel dan 28.219 penginapan. Sedangkan jumlah koperasi di Indonesia paling banyak adalah koperasi simpan pinjam sejumlah 35.686 (Data Badan Pusat Statistik 04310.2101). Kondisi ini dipengaruhi karena meningkatnya permintaan akan pembangunan dan pertumbuhan pada sektor properti di Indonesia. Pemerintah saat ini sedang gencar melakukan pembangunan infrastruktur di berbagai wilayah di Indonesia. Dengan membangun berbagai infrastruktur ini, diharapkan dapat memompa laju pertumbuhan ekonomi di Indonesia.

Pada era sekarang, seiring dengan peningkatan pertumbuhan jumlah penduduk yang tinggi dibutuhkan pula sarana penunjang kehidupan berupa infrastruktur yang nyaman dan aman untuk memenuhi kebutuhan hidup. Dalam usaha memenuhi kebutuhan sehari hari salah satu upayanya adalah dengan dilaksanakan pembangunan infrastruktur dengan kualitas yang tinggi namun diusahakan dengan pelaksanaan pekerjaan konstruksi yang cepat dengan hasil yang bagus dan biaya yang efisien. Beton menjadi salah satu komponen penting dalam pembangunan suatu infrastruktur. Beton dipilih sebagai bahan utama karena harga yang lebih ekonomis dan bahan baku yang dibutuhkan dalam pembuatan mudah untuk ditemukan (pasir, semen, kerikil, air). Selain itu pekerjaan beton juga relatif lebih mudah dalam perawatannya. Beton sering digunakan dalam konstruksi bangunan dikarenakan memiliki kuat tekan yang tinggi dan tahan terhadap pengaruh air dalam waktu yang lama, namun di sisi lain beton memiliki kelemahan dalam kuat tariknya.

Beton tersusun dari campuran kerikil, pasir, air, dan semen. Industri pembuatan beton yang memilih semen portland sebagai bahan utamanya yang dapat menimbulkan kerusakan terhadap lingkungan. Kerusakan terhadap lingkungan dapat terjadi disebabkan emisi karbon dioksida yang berasal dari proses kalsinasi kapur dan pembakaran batu bara dalam pembuatan semen portland. Salah satu alternatif solusi untuk menggantikan semen portland yaitu menggunakan hasil pembakaran batu bara atau fly ash guna meningkatkan kualitas beton dan mengurangi efek buruk terhadap lingkungan. Pada penelitian ini penggunaan abu terbang (fly ash) digunakan dengan maksud mengurangi dampak buruk terhadap lingkungan dengan pemanfaatan kembali residu pembakaran batu bara pada PLTU yaitu berupa abu terbang (fly ash), Abu terbang sendiri adalah abu yang mempunyai sifat pozzolan hasil dari pembakaran batu bara jenis antrasit pada suhu $1560^{\circ} \mathrm{C}$, berukuran antara $1-150$ mikrometer dengan kadar oksida terbanyak di dalam fly ash adalah silica $\left(\mathrm{SiO}_{2}\right)$ sebanyak $60-70 \%$ berat. (Caroles, 2019). Sifat kimia yang berguna sebagai pengikat dalam pembuatan beton atau sifat pozzolan yang sama dengan semen, dengan sifat demikian abu terbang (fly ash) dapat berfungsi dalam sebagai pengganti semen dalam pembuatan beton serta dapat meningkatkan kualitas beton sendiri. Dengan konsep tersebut, dapat diperoleh beton yang mudah dikerjakan (workability), berkualitas tinggi (good performance), dan daya tahan tinggi (durability). (Mehta, 2006).

Pada penelitian ini mengkaji pengujian kuat tarik langsung beton dan kuat tarik belah beton dengan bahan pengganti semen fly ash kadar 15\%, 30\% dan 40\% terhadap beton normal pada usia beton 28 hari dengan ukuran agregat untuk beton normal fly ash adalah maksimum $2 \mathrm{~cm}$. Dengan parameter ukuran agregat dan variasi fly ash tersebut belum pernah diteliti sebelumnya dan parameter tersebut sangat penting terutama dalam penentuan mutu dari beton. Variasi fly ash kadar 15\%, 30\% dan 40\% akan menghasilkan sifat-sifat beton yang berbeda, sehingga perlu dianalisis pengaruhnya. Pada penelitian ini diharapkan dapat menjadi acuan ataupun evaluasi dan dapat diaplikasikan serta bermanfaat bagi kemajuan dalam dunia konstruksi.

\section{Landasan Teori}

Beton adalah campuran semen portland atau semen hidrolis lainnya, agregat halus, agregat kasar, dan air, dengan atau tanpa bahan tambahan (SNI 2847:2019). Seiring dengan penambahan umur, beton akan semakin mengeras dan akan mencapai mutu rencana pada usia 28 hari. Beton memiliki kekuatan yang besar dalam kuat tekan dengan demikian beton dipilih menjadi salah satu komponen utama dalam pembuatan struktur suatu infrastruktur. Beton disusun dari agregat kasar dan agregat halus. Agregat kasar yang dipakai biasanya berupa batu alam sedangkan agregat halus yang dipakai biasanya berupa pasir yang keduanya dapat didapat di alam maupun pada industri pembuatan. 
Pembuatan beton yang dapat menggunakan substitusi semen melalui penggunaan fly ash atau abu terbang dinilai dapat mengurangi penggunaan semen yang berdampak buruk pada lingkungan. Fly ash adalah produk dari produk sampingan hasil pembakaran batu bara pada Pembangkit Listrik Tenaga Uap (PLTU) (Marthinus et al, 2015). SNI 03-6414-2002 mendefinisikan pengertian fly ash/abu terbang adalah limbah hasil pembakaran batu bara pada tungku pembangkit listrik tenaga uap yang berbentuk halus, bundar dan bersifat pozolanik. Abu terbang (fly ash) ini merupakan salah satu hasil sampingan (by product) industri yang bersifat pozzolan dan dapat menjadi bahan pengikat (binder) pada pembuatan beton. Pozzolan adalah bahan yang terdiri dari alumunium dan silika yang bereaksi dengan kalsium hidroksida secara kimia pada temperatur ruangan serta serta dapat membentuk suatu senyawa bersifat cementitious. Sehingga dengan kandungan tersebut fly ash dapat menjadi bahan pengganti semen. Untuk beton mutu tinggi FAS yang digunakan antara 0,28-0,38 sedangkan untuk beton bermutu sangat tinggi menggunakan faktor air semen kurang dari 0,2. (Faisal, 2019).

Nilai tegangan maksimum beton HVFA - SCC kadar $50 \%$ sebesar 3,5 MPa. Sedangkan nilai regangan maksimum beton HVFA-SCC kadar 50\% sebesar 0,00140 (Pratama, 2020). Pengujian kuat tarik langsung menggunakan alat pengujian UTM (Universal Testing Machine) dan pengujian kuat tarik belah menggunakan alat pengujian CTM (Compression Testing Machine) kemudian dapat diambil data dan grafik perbandingan pengujian per variasi $15 \%, 30$ $\%, 40 \%$ dan beton normal.

\section{METODE}

Metode penelitian yang digunakan pada penelitian ini berbasis eksperimental. Penelitian yang dilaksanakan berdasarkan percobaan benda uji yang didapat agar mencapat suatu data dan hasil dalam kondisi yang terkontrol. dilakukan secara sistematis yang nantinya dibandingkan dengan hasil benda uji pembanding agar didapatkan hasil penelitian yang sesuai rencana dan dapat dipertanggungjawabkan. Penelitian ini bertujuan untuk mengetahui perbandingan nilai kuat tarik langsung beton dan nilai kuat tarik belah beton normal dengan bahan tambah semen $f l y$ ash kadar 15\%,30\% dan 40\% pada umur 28 hari. Penelitian dilakukan pada benda uji masing-masing berjumlah tiga benda uji beton normal dengan kadar fly ash 15\%,30\% dan 40\% untuk benda uji untuk pengujian kuat tarik langsung dengan dimensi penampang yaitu $10 \mathrm{~cm} \times 10 \mathrm{~cm} \times 25 \mathrm{~cm}$ sedangkan untuk pengujian kuat tarik belah dengan dimensi penampang yaitu berbentuk tabung dengan tinggi $30 \mathrm{~cm}$ dan diameter $15 \mathrm{~cm}$.. Jumlah benda uji dapat dilihat pada Tabel 1 dibawah ini.

Tabel 1. Benda uji kuat tarik langsung dan uji kuat tarik belah

\begin{tabular}{clll}
\hline No. & Tipe Benda Uji & Kadar Fly Ash & Jumlah \\
\hline 1 & Normal Concrete & - & 6 \\
2 & Fyy Ash Concrete & $15 \%$ & 6 \\
3 & Fy Ash Concrete & $30 \%$ & 6 \\
4 & Fly Ash Concrete & $40 \%$ & 6 \\
\hline \multicolumn{3}{c}{ Jumlah Total } & 24 \\
\hline
\end{tabular}

\section{Tahap Studi Literatur dan Persiapan}

Tahap paling dasar yang dilakukan yaitu studi literatur terhadap topik yang berkaitan. Studi literatur diambil dari berbagai sumber, seperti referensi buku, jurnal penelitian, serta website internet yang berkorelasi. Tahap ini juga sudah dipersiapkan material meliputi segala alat dan bahan yang diperlukan dalam proses penelitian. Survey terhadap penentuan material yang akan dipakai diperlukan agar memperoleh material dengan kualitas yang bagus dan bernilai ekonomis agar didapat hasil yang maksimal.

\section{Tahap Pengujian Material}

Tahap pengujian material ini dilaksanakan pengujian secara bertahap dengan material-material yang telah dipilih meliputi agregat kasar, agregat halus, fly ash, semen, dan baja tulangan. Sehingga sifat dan karakteristik material yang akan dipakai dapat diketahui. Data dari pengujian material sangat diperlukan sebagai acuan dalam penentuan mix design dalam pembuatan perencanaan mutu beton ataupun hasil kesimpulan penelitian agar didapatkan hasil yang maksimal.

\section{Tahap Mix Design}

Tahap mix design dilakukan untuk menentukan komposisi material yang digunakan untuk membuat campuran beton sesuai dengan kuat tekan yang diinginkan. Untuk jenis beton normal menggunakan acuan SNI 7656 tahun 2012. 
Tahap perencanaan dalam pembuatan untuk $1 \mathrm{~m}^{3}$ beton pada penelitian ini memiliki tujuan untuk mendapatkan kadar proporsi campuran material agar beton memenuhi persyaratan umum maupun yang sesuai dengan perencanaan mutu beton. Mix design yang digunakan mengacu pada SNI 7656 tahun 2012 dengan mengganti semen dengan variasi kadar fly ash 15\%, 30\%, dan 40\% terhadap volume total semen. Perhitungan mix design secara lengkap disajikan dalam Tabel 2 dibawah ini.

Tabel 2. Rekapitulasi mix design per $1 \mathrm{~m}^{3}$

\begin{tabular}{lllll}
\hline \multirow{2}{*}{ Material } & \multicolumn{4}{c}{ Jenis Beton } \\
\cline { 2 - 5 } & Normal & \multicolumn{3}{c}{ Normal dengan Kadar $\boldsymbol{F l y ~} \boldsymbol{A s h}$} \\
\cline { 3 - 5 } & & $\mathbf{1 5 \%}$ & $\mathbf{3 0 \%}$ & $\mathbf{4 0 \%}$ \\
\hline Fy $A s h\left(\mathrm{~kg} / \mathrm{m}^{3}\right)$ & - & 42,71 & 85,42 & 113,89 \\
Semen $\left(\mathrm{kg} / \mathrm{m}^{3}\right)$ & 284,72 & 242,01 & 199,31 & 170,83 \\
Pasir $\left(\mathrm{kg} / \mathrm{m}^{3}\right)$ & 847,20 & 847,20 & 847,20 & 847,20 \\
Kerikil $\left(\mathrm{kg} / \mathrm{m}^{3}\right)$ & 924 & 924 & 924 & 924 \\
Air $\left(\mathrm{lt} / \mathrm{m}^{3}\right)$ & 205 & 205 & 205 & 205 \\
\hline
\end{tabular}

\section{Tahap Pembuatan Benda Uji}

Tahap pembuatan benda uji pada penelitian ini dengan dimensi benda uji pengujian kuat tarik langsung $10 \mathrm{x} 10 \mathrm{x}$ $25 \mathrm{~cm}$ berbentuk balok dengan ditengah bentang terdapat cuilan berbentuk segitiga dengan dimensi tinggi $1,5 \mathrm{~cm}$ dan alas $2 \mathrm{~cm}$ berfungsi sebagai area yang diharapkan gagal dan benda uji pengujian kuat tarik belah berupa silinder $15 \mathrm{~cm}$ dan tinggi $30 \mathrm{~cm}$. Sebelum campuran beton dimasukkan kedalam bekisting harus dilakukan pengujian beton segar terlebih dahulu. Untuk jenis beton normal pengujian yang dilakukan adalah slump test.

\section{Tahap Perawatan Beton (Curing)}

Curing pada penelitian ini dilakukan setelah beton silinder dilepas dari mould dengan cara menutupi beton silinder menggunakan karung goni yang dibasahi hingga mendekati umur pengujian beton. Waktu pengeringan balok dibutuhkan kurang lebih 7 hari sebelum beton akan diuji dengan tujuan agar beton yang diuji dalam keadaan kering sempurna tidak ada pengaruh basah dari curing yang sudah dilakukan, dengan curing diharapkan saat pengujian balok didapatkan hasil sesuai dengan perencanaan serta menjaga beton hasil cetakan dari perbedaan suhu dengan lingkungan sehingga tidak mengalami retakan.

\section{Tahap Pengujian Kuat Tarik Langsung}

Tahap pengujian kuat tarik langsung dilaksanakan terhadap benda uji berupa balok berdimensi $10 \times 10 \times 25 \mathrm{~cm}$. Benda uji uji tarik langsung mendapat beban berupa tarikan dari bawah, dan bagian atas sebagai penahan, data-data yang diperoleh pada pengujian kuat tarik langsung meliputi data beban (load) yang diperoleh dari pembacaan load indicator pada alat UTM (Universal Testing Machine) Pengujian kuat tarik langsung dapat dihitung dengan rumus sebagai berikut :

$$
f_{t}=\frac{P}{A}
$$

Keterangan,

$$
\begin{array}{ll}
\mathrm{f}_{\mathrm{t}} & =\text { kuat tarik langsung dalam }\left(\mathrm{N} / \mathrm{mm}^{2}\right) \\
\mathrm{P} & =\text { beban maksimum yang mampu ditahan }(\mathrm{N}) \\
\mathrm{A} & =\text { luas penampang efektif dalam }\left(\mathrm{mm}^{2}\right)
\end{array}
$$

\section{Tahap Pengujian Kuat Tarik Belah}

Tahap pengujian kuat tarik belah dilaksanakan terhadap benda uji berbentuk silinder berdiameter $15 \mathrm{~cm}$ dan tinggi $30 \mathrm{~cm}$. Benda uji kuat tarik belah diperoleh dari hasil pembebanan maksimum dengan posisi benda uji mendatar sejajar dengan permukaan alas pembebanan pada alat. Pada pengujian tarik belah meliputi data beban maksimum ( $\mathrm{P}_{\text {maks }}$ yang diperoleh dari pembacaan Load Indicator yang diperoleh pada alat CTM (Compression Testing Machine). Pengujian kuat tarik langsung dihitung dengan rumus sebagai berikut :

$$
f^{\prime} t=\frac{2 P}{\pi L D}
$$

Keterangan:

$\mathrm{ft}=$ kuat tarik beton $(\mathrm{MPa})$ 
$\mathrm{P} \quad=$ beban uji maksimum $(\mathrm{N})$

$\mathrm{L} \quad=$ panjang benda uji $(\mathrm{mm})$

$\mathrm{D}=$ diameter benda uji $(\mathrm{mm})$

\section{HASIL DAN PEMBAHASAN}

\section{Pengujian Beton Segar}

Tahap pengujian pasca dilakukan mixing adalah slump test untuk jenis beton normal mengacu pada syarat PBI 1971 (Peraturan Beton Indonesia). Hasil pengujian dapat dilihat pada tabel 3 dibawah ini.

Tabel 3. Hasil pengujian Slump Test beton normal, FAC 15\% dan HVFAC 50\%

\begin{tabular}{llll}
\hline Beton & T (cm) & $\begin{array}{l}\text { Syarat PBI } \\
\mathbf{1 9 7 1}(\mathbf{c m})\end{array}$ & Keterangan \\
\hline Kuat Tarik Langsung & & & \\
\hline Normal Concrete & $9,5 \mathrm{~cm}$ & $7,5-15$ & Memenuhi \\
Kadar Fly Ash $15 \%$ & $9 \mathrm{~cm}$ & $7,5-15$ & Memenuhi \\
Kadar Fy Ash $30 \%$ & $12 \mathrm{~cm}$ & $7,5-15$ & Memenuhi \\
Kadar Fly Ash $40 \%$ & $8,5 \mathrm{~cm}$ & $7,5-15$ & Memenuhi \\
\hline Kuat Tarik Belah & & & \\
\hline Normal Concrete & $9,5 \mathrm{~cm}$ & $7,5-15$ & Memenuhi \\
Kadar Fly Ash $15 \%$ & $9 \mathrm{~cm}$ & $7,5-15$ & Memenuhi \\
Kadar Fly Ash $30 \%$ & $12 \mathrm{~cm}$ & $7,5-15$ & Memenuhi \\
Kadar Fly Ash $40 \%$ & $8,5 \mathrm{~cm}$ & $7,5-15$ & Memenuhi \\
\hline
\end{tabular}

\section{Hasil Pengujian Kuat Tarik Langsung Beton}

Pengujian kuat tarik langsung beton digunakan alat UTM (Universal Testing Machine) sampel yang digunakan adalah balok dengan dimensi Panjang $10 \mathrm{~cm}$, lebar $10 \mathrm{~cm}$ dan tinggi $25 \mathrm{~cm}$, yang diuji pada saat umur beton mencapai 28 hari. Hasil pengujian kuat tarik langsung beton yang disajikan pada tabel 4 sebagai berikut

Tabel 4. Hasil pengujian kuat tarik langsung

\begin{tabular}{lllllc}
\hline Benda Uji & $\begin{array}{l}\text { Luas } \\
\left(\mathbf{m m}^{2}\right)\end{array}$ & $\begin{array}{l}\text { Beban Maks } \\
\mathbf{( N )}\end{array}$ & $\begin{array}{l}\text { Kuat Tarik } \\
\mathbf{( M P a )}\end{array}$ & $\begin{array}{l}\text { Rata-rata Kuat } \\
\text { Tarik } \mathbf{( M P a )}\end{array}$ & COV \\
\hline NC-1 & 7000 & 1677,11 & 2,34 & & 0,0069 \\
NC-2 & 7000 & 18730,70 & 2,45 & 2,49 & \\
NC-3 & 7000 & 17161,64 & 2,68 & & 0,048 \\
\hline FA15\%-1 & 7000 & 20495,90 & 2,93 & & \\
FA15\%-2 & 7000 & 21574,63 & 3,08 & & 0,025 \\
FA15\%-3 & 7000 & 22555,29 & 3,22 & & \\
\hline FA30\%-1 & 7000 & 20593,96 & 2,81 & \\
FA30\%-2 & 7000 & 19662,33 & 2,93 & \\
FA30\%-3 & 7000 & 20495,90 & 2,94 & & \\
\hline FA40\%-1 & 7000 & 17651,97 & 2,52 & & \\
FA40\%-2 & 7000 & 18338,44 & 2,55 & 2,56 & \\
FA40\%-3 & 7000 & 17848,1 & 2,62 & & \\
\hline
\end{tabular}

Dari data pada tabel 4 dapat dibuat grafik perbandingan kuat tarik langsung antara beton normal dengan beton fly ash kadar 15\%, 30\%, dan 40\% yang akan disajikan pada gambar 1. 


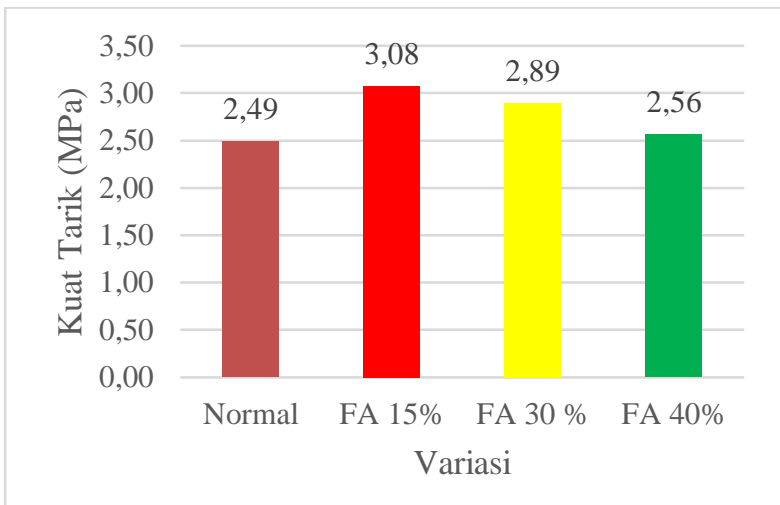

Gambar 1. Grafik perbandingan nilai kuat tarik langsung beton dengan bahan pengganti semen fly ash kadar 15\%, $30 \%$, dan $40 \%$ terhadap beton normal

Dari pengujian kuat tarik langsung beton menghasilkan grafik di atas yang menunjukkan kuat tarik rata-rata, dengan bahan pengganti semen fly ash dengan kadar 15\%, 30\%, $40 \%$ dan beton normal berturut-turut 3,08 MPa, 2,89 $\mathrm{MPa}, 2,56 \mathrm{MPa}$ dan beton normal sebesar 2,49 MPa. Sesuai grafik di atas dapat diprediksi kuat tarik langsung beton dengan bahan pengganti semen fly ash kadar 15\%, 30\%, $40 \%$ dan beton normal paling efektif adalah pada kadar 15\%. Hasil ini selaras dengan penelitian Merry N. M. Kosakoy, 2017, yaitu dengan fly ash sebagai pengganti semen dengan kadar sebesar 15\% dari volume binder dapat meningkatkan nilai kuat tarik pada beton.

\section{Hasil Pengujian Kuat Tarik Belah Beton}

Pengujian kuat tarik belah beton digunakan alat CTM (Compression Testing Machine). Sampel yang digunakan adalah silinder dengan diameter $15 \mathrm{~cm}$ dan tinggi $30 \mathrm{~cm}$, yang diuji pada saat umur beton mencapai 28 hari. Hasil pengujian kuat tarik belah beton yang disajikan pada tabel 5 sebagai berikut

Tabel 5. Hasil pengujian kuat tarik belah

\begin{tabular}{lllllll}
\hline Benda Uji & Ls $(\mathbf{m m})$ & $\mathbf{D}(\mathbf{m m})$ & $\begin{array}{l}\text { P maks } \\
\mathbf{( N )}\end{array}$ & $\mathbf{f t}$ & $\begin{array}{l}\text { Rata-rata } \\
\mathbf{f t}\end{array}$ & COV \\
\hline NC-1 & 300 & 149 & 210000 & 2,99 & & \\
NC-2 & 299 & 149 & 225000 & 3,22 & 3,04 & 0,053 \\
NC-3 & 300 & 150 & 205000 & 2,90 & & \\
\hline FA15\%-1 & 300 & 150 & 275000 & 3,89 & & \\
FA15\%-2 & 300 & 149 & 290000 & 4,13 & 3,87 & 0,069 \\
FA15\%-3 & 295 & 150 & 250000 & 3,60 & & \\
\hline FA30\%-1 & 300 & 150 & 160000 & 2,26 & & \\
FA30\%-2 & 300 & 149 & 170000 & 2,42 & 2,34 & \\
FA30\%-3 & 300 & 149 & 165000 & 2,35 & & \\
\hline FA40\%-1 & 298 & 148 & 145000 & 2,09 & & \\
FA40\%-2 & 298 & 150 & 135000 & 1,92 & 2,08 & \\
FA40\%-3 & 300 & 148 & 155000 & 2,22 & & \\
\hline
\end{tabular}

Dari data pada tabel 5 dapat dibuat grafik perbandingan kuat tarik belah antara beton normal dengan beton fly ash kadar 15\%,30\%, dan 40\% yang akan disajikan pada gambar 2 . 


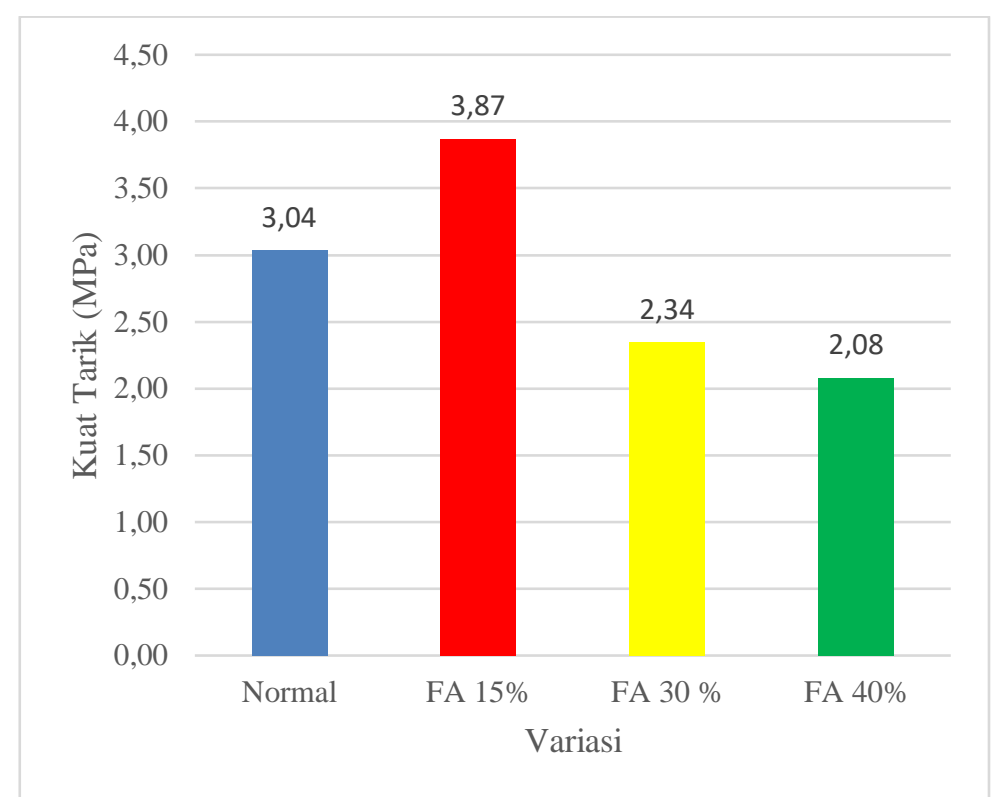

Gambar 2. Grafik perbandingan nilai kuat tarik belah beton dengan bahan pengganti semen fly ash kadar 15\%, $30 \%$, dan $40 \%$ terhadap beton normal

Grafik diatas menunjukkan kuat tarik rata-rata dari pengujian kuat tarik belah beton dengan bahan pengganti semen fly ash kadar 15\%, 30\%, $40 \%$ dan beton normal berturut-turut 3,87 MPa, 2,34 $\mathrm{MPa}, 2,08 \mathrm{MPa}$ dan beton normal sebesar 3,04 MPa. Sesuai grafik diatas dapat diprediksi kuat tarik langsung beton dengan bahan pengganti semen fly ash kadar 15\%, 30\%, $40 \%$ dan beton normal paling efektif adalah pada kadar 15\%. Hasil ini selaras dengan penelitian Adrian Philip Marthinus, 2015, hubungan kuat tarik belah dan presentase abu terbang 30\% hingga 70\% menunjukan model grafik di mana terjadi kenaikan kuat tarik belah pada beton seiring menurunnya presentase $f l y$ ash pada beton. Pada kondisi presentase fly ash $0 \%$ maka nilai kuat tarik belah berada pada kondisi maksimum, namun pada presentase fly ash 70\% maka nilai kuat tarik belah berada pada kondisi minimum

\section{Perbandingan Hasil Pengujian Kuat Tarik Langsung dengan Kuat Tarik Belah}

Berdasarkan data pengujian kuat tarik langsung beton dengan pengujian kuat tarik belah beton dengan variasi kadar $15 \%, 30 \%, 40 \%$ dan beton normal yang disajikan pada tabel 6 sebagai sebagai berikut

Tabel 6. Perbandingan per variasi rata-rata kuat tarik langsung dengan rata-rata kuat tarik belah

\begin{tabular}{|c|c|c|c|}
\hline Jenis Beton & $\begin{array}{c}\text { Kuat Tarik Langsung } \\
\text { (MPa) }\end{array}$ & $\begin{array}{c}\text { Kuat Tarik Belah } \\
\text { (MPa) }\end{array}$ & $\frac{\mathrm{fct}}{\mathrm{f}^{\prime} \mathrm{t}}(\%)$ \\
\hline FA-15\% & 3,08 & 3,87 & $79,47 \%$ \\
\hline FA-30\% & 2,89 & 2,34 & $123,37 \%$ \\
\hline FA- $40 \%$ & 2,56 & 2,08 & $123,29 \%$ \\
\hline $\mathrm{NC}$ & 2,49 & 3,04 & $82,00 \%$ \\
\hline
\end{tabular}

Dari tabel 6 dapat dilihat nilai pengujian rata-rata kuat tarik beton pada pengujian kuat tarik belah lebih besar dibandingkan dengan nilai rata-rata kuat tarik pada beton dengan pengujian kuat tarik langsung, nilai kuat tarik langsung pada variasi fly ash kadar $15 \%$ sebesar 79,47\% dari kuat tarik belah, nilai kuat tarik langsung pada variasi fly ash kadar $30 \%$ sebesar 123,37\% dari kuat tarik belah, nilai kuat tarik langsung pada variasi fly ash kadar $40 \%$ sebesar 123,29\% dari kuat tarik belah, nilai kuat tarik langsung pada variasi beton normal sebesar $82 \%$ dari kuat tarik belah. Dalam pengujian kuat tarik belah, tegangan yang dihasilkan pada benda uji merupakan suatu tegangan tekan, hal ini terjadi karena pengaruh oleh perlemahan penampang pada percobaan tarik langsung jauh lebih sensitif daripada perlemahan pada uji tarik belah, pengujian kuat tarik langsung lebih sensitif dibandingkan dengan perlemahan pada pengujian kuat tarik belah. Nilai pengujian kuat tarik langsung cenderung mendekati nilai kuat tarik sebenarnya hal ini disebabkan benda uji dalam pengujian kuat tarik langsung menahan tegangan tarik yang sama besar pada seluruh penampang. 


\section{SIMPULAN}

Berdasarkan penelitian dan analisis pada pengujian kuat tarik langsung dan kuat tarik belah dengan bahan pengganti semen fly ash kadar $15 \%$, $30 \%$ dan $40 \%$ terhadap beton normal dapat diambil kesimpulan sebagai berikut:

1. Penambahan abu terbang (fly ash) dapat meningkatkan hasil kuat tarik langsung dari beton dibandingkan beton normal tanpa penambahan abu terbang (fly ash).

2. Penambahan abu terbang $(f y$ ash) dapat meningkatkan kuat tarik belah dari beton dibandingkan beton normal tanpa penambahan abu terbang (fly ash).

3. Nilai pengujian rata-rata kuat tarik beton pada pengujian kuat tarik belah lebih besar dibandingkan dengan nilai rata-rata kuat tarik pada beton dengan pengujian kuat tarik langsung, nilai kuat tarik langsung pada variasi fly ash kadar $15 \%$ sebesar 79,47 \% dari kuat tarik belah, nilai kuat tarik langsung pada variasi fly ash kadar 30 $\%$ sebesar 123,37 \% dari kuat tarik belah, nilai kuat tarik langsung pada variasi fly ash kadar $40 \%$ sebesar $123,29 \%$ dari kuat tarik belah, nilai kuat tarik langsung pada variasi beton normal sebesar $82 \%$ dari kuat tarik belah.

\section{REFERENSI}

Badan Pusat Statistik, 2020, "Statistik Infrastruktur Indonesia 2020 (Hasil Pemutakhiran Data Perkembangan Desa 2020)".

Caroles, J. D. S., 2019, “Ekstraksi Silika yang Terkandung Dalam Limbah Abu Terbang Batu Bara”, Fullerene Journal of Chemistry. Vol. 4 No. 1, pp. 5-7.

Kementrian PPN/Bappenas, 2019, "Rencana Pembangunan Jangka Menengah Nasional 2020-2024 (Indonesia Berpenghasilan Menengah - Tinggi yang Sejahera, Adil, dan Berkesinambungan".

Marthinus A. P., Sumajouw M. D., dan Windah R. S., 2015, "Pengaruh Penambahan Abu Terbang (Fly Ash) Terhadap Kuat Tarik Belah Beton". Jurnal Sipil Statik. Vol. 3 No. 11.

Mehta, P. K.. 2006. "High Performance, High Volume Fly Ash Concrete for Sustainable Development", Proceedings of the International Workshop on Sustainable Development \& Concrete Technology, pp. 3-14.

Tjokrodimuljo, K., 2007, “Teknologi Beton”, Jurusan Teknik Sipil, Fakultas Teknik Universitas Gadjah Mada. Yogyakarta.

Umboh A. H., Sumajouw M. D., dan Windah R. S., 2014, "Pengaruh Pemanfaatan Abu Terbang (Fly Ash) dari PLTU II Sulawesi Utara Sebagai Substitusi Parsial Semen Terhadap Kuat Tekan Beton", Jurnal Sipil Statik. Vol. 2 No. 7.

Kosakoy M. N. M., Wallah S. E., dan Pandaleke R., 2017, "Perbandingan Nilai Kuat Tarik Langsung dan Tidak Langsung Pada Beton yang Menggunakan Fly Ash", Jurnal Sipil Statik. Vol. 5 No. 7.

Pandaleke R. E., dan Windah R. S., 2017, "Perbandingan Uji Tarik Langsung dan Uji Tarik Belah Beton”, Jurnal Sipil Statik. Vol. 5 No. 10.

Pratama, 2020, "Kajian Kuat Tarik Langsung Beton Memadat Sendiri dengan Kadar Fly Ash 50\% dan 60\%".

Yudhanto F. A., Budi, A. S., dan Saifullah, H. A., 2019, "Kajian Uji Tarik Beton HVFA Memadat Sendiri Terhadap Beton Normal”, Matriks Teknik Sipil. Vol. 7 No.4, pp. 423-429. 